\title{
A Tailored Nutrition Education Intervention Improves Women's Nutrition Knowledge and Dietary Practices in Farming Households of Tanzania
}

\author{
Nyamizi Bundala ${ }^{1,2 *}$, Joyce Kinabo ${ }^{1}$, Theresia Jumbe ${ }^{1}$, Constance Rybak ${ }^{2}$, Wolfgang Stuetz ${ }^{4}$ and Stefan Sieber ${ }^{2,3}$ \\ ${ }^{1}$ Department of Food Technology, Nutrition and Consumer Sciences, Sokoine University of Agriculture, P. O. Box 3006, Morogoro, Tanzania
}

${ }^{2}$ Leibniz Centre for Agricultural Landscape Research (ZALF e. V), Eberswalder Str. 84, 15374 Müncheberg, Germany

${ }^{3}$ Department of Agricultural Economics, Humboldt University of Berlin, Rudower Chausee 16, 10099 Berlin, Germany

${ }^{4}$ Institute of Nutritional Sciences, University of Hohenheim, Stuttgart 70599, Germany

Received: 23 December, 2019; Accepted: 20 January, 2020; Published: 17 February, 2020

*Corresponding author: Nyamizi Bundala,Department of Food Technology, Nutrition and Consumer Sciences, Sokoine University of Agriculture, P. O. Box 3006, Morogoro, Tanzania, E-mail: nyamizihashim@gmail.com

\begin{abstract}
A study was carried out to assess the effectiveness of a nutrition education intervention among women residing in the villages of Dodoma and Morogoro regions of Tanzania. Prior to the intervention, a baseline survey was conducted in July-August 2016. The survey involved 663 women who completed a pre-test assessment for nutrition knowledge and practice and enrolled in nutrition education intervention. The intervention was carried out for 8 months (September 2017 to April 2018) including a 10 days group training per village with six-month individual training follow-ups in the household. Spouses/ adult men were also invited to participate in the intervention. Training content included; functions of food, food groups, malnutrition, food preparations, food consumption and homestead food production. Women were given a post-test during the endline survey (July-August 2018) to assess the intervention. Nutrition knowledge (NK), Nutrition Practice (NP) as well as a combination of Nutrition Knowledge and Practice (NKP) were computed using a scoring method as per FAO guidelines. The test was scored in a range of 0-10 for NK and NP and 0-20 for NKP. The median scores before and after the intervention were compared using the Wilcoxon signed-rank test. The NKP scores among sub-groups of respondents were computed using Mann-Whitney and Kruskal Wallis tests. Changes in proportions were calculated using a McNemar test. Results indicated a significant increase in the post-intervention median scores (interquartile range) than the pre-intervention median scores (interquartile range) for NK, NP, and NKP; $7(5,7)$ vs $4(3,5), 5(4,6)$ vs $3(2,4)$ and $12(10,13)$ vs $7(5,9)$ respectively, p<0.01. Higher scores were found among those who had received nutrition education, those who had frequently been exposed to nutrition education, those whose spouses/men participated in the intervention and those with a formal level of education than their counterparts. A significant increase in the frequencies of consumption of vegetables, fruits and legumes were noted from the baseline to the post-intervention phase in the end-line $(87 \%-98 \%, 63 \%-69 \%$ and $76 \%-87 \%$ ) respectively. The findings suggest the effectiveness of the nutrition education in the promotion of nutrition knowledge and desirable dietary practices in farming households of Tanzania.
\end{abstract}

Keywords: Nutrition education; Tailored training; Dietary practices; Nutrition knowledge; Food consumption; Rural households

\section{Introduction}

Malnutrition exists in various forms, affects many people and is the leading cause of ill-health worldwide $[1,2,3]$. Globally stunting affects $22 \%$ of children below the age of 5 years, while $39 \%$ of the adult population are overweight or obese, and about one-third of all women of reproductive age are anaemic [1]. The conceptual framework of malnutrition highlights the causative levels of malnutrition with a poor dietary intake being among the immediate causes of it [3]. The presence of foods alone does not necessarily translate into an optimal dietary intake. However, the choice of what, how, and when to eat is governed by several factors of which nutrition literacy is among the tops $[4,5,6]$. Studies have shown that poor dietary intake is linked with a high level of nutritional illiteracy in the population [7,8]. A poor dietary intake is a modifiable risk factor for dietary-related conditions such as nutrition deficiencies, overweight, obesity and non-communicable diseases $[5,9,10,11]$. Unfortunately, the burden of these malnutrition conditions affects low and middleincome countries more than high-income countries because, historically, these countries are inflicted with undernutrition and are more affected by the rise of overweight, obesity and noncommunicable diseases $[1,12]$.

In Tanzania, the levels of malnutrition are still high for both women of reproductive age and children below five years of age. Currently, stunting affects $31.8 \%$ of children below five years of age while overweight and obesity for women of reproductive age increased its toll from $28 \%$ in 2015 to $31.7 \%$ in 2018 $[13,14]$. Feeding practices are also sub-optimal, with only $30 \%$ of children below five years of age are fed the minimum acceptable diet [13]. The country has been implementing interventions to scale-up nutrition such as the provision of folic acid and iron supplements to pregnant women, vitamin A supplementations 
to children below five years of age and fortifications of staple foods with micronutrients of public health importance [15]. All these interventions need to be accompanied by a component of nutrition education and behaviour change communication, to increase their utilization, but this is not usually included in the programmes $[5,16]$. Nutrition education is defined as any combination of educational strategies accompanied by environmental supports, designed to facilitate the voluntary adoption of food choices and other food and nutrition-related behaviour conducive to health and well-being [17]. This suggests the potential of nutrition education in modulating dietary practices and therefore improves consumption and nutrition status.

Studies have shown that poor knowledge related to food consumption may affect dietary practices and suggest the need for behavioural change in the community $[7,8,18,19,20]$. While several studies regarding the positive impact of nutrition education on behaviour/change exist in Tanzania;the focus has been on the child feeding and nutrition status [20-25]. Effect of nutrition education on overall household dietary practices is not given much attention especially in rural parts of the country where the burden of malnutrition is high. Therefore, this study aimed to assess the effect of nutrition education on nutritionrelated knowledge and dietary practices among women/ caregivers in rural farming households of Dodoma and Morogoro regions, Tanzania.

\section{Methods}

\section{Study Area}

The study was part of the Scaling-up Nutrition project (scale- $\mathrm{N}$ ), which was implemented in Dodoma and Morogoro regions, Tanzania[7,26,27]. These two regions differ in terms of agro-ecological characteristics (NBS 2015). Morogoro is located on the sub-humid climate while Dodoma features a semi-arid climate. In terms of food production, Morogoro is termed as a highly productive and food secured region while Dodoma is not, hence experience food inadequacy $[27,28]$. Despite these agroecological differences, these regions have a high prevalence of stunting and iron deficiency anaemia [14]. To understand the variations between two regions, data were collected from two purposively selected districts, one from each region. These districts were Kilosa from Morogoro region and Chamwino from Dodoma region. From each district, two villages were randomly chosen: Mzula and Chinoje in Chamwino district and Tindinga and Mhenda in Kilosa district [7,18,26,27].

\section{Study Design, Participants and Sampling}

This is a pre-post intervention study, utilizing both baseline and end-line data. The baseline data were collected on July-August 2016 while the end-line data were collected two years later in JulyAugust 2018 following the intervention of nutrition education. The selection of study participants is described elsewhere $[7,26]$. This study received ethical approval from the National Institute for Medical Research in Tanzania (NIMR) with Reference number
NIMR/HQ/R.8a/Vol. IX/2226. In addition, mothers/caregivers and heads of households consented to participate in the study.

\section{Description of Nutrition Education Intervention}

Development of the nutrition education intervention involved different stages including; i) identification of the dietary gaps, ii) participatory analysis of the solutions iii) designing of nutrition education training packages and iv) the implementation of nutrition education training.

\section{i. Identification of Dietary Gaps}

The development of nutrition education intervention was grounded by the findings from the baseline survey, which was carried out during the initial phase of the Scale-N project. The findings of the baseline survey revealed several gaps and challenges including; high levels of nutrition illiteracy as well as inadequate skills related to food preparation, cooking, food allocation and undesirable food consumption practices [7]. Furthermore, community members especially men indicated that nutrition education was mainly given through health care providers in health centres targeting pregnant women or women with children below 5 years of age who attend to their scheduled antenatal clinic visits. Other community members especially men are left out in nutrition programmes. Figure one summarises the main dietary gaps found during the baseline survey. The detailed information on the dietary gaps is previously described in [7].

\section{ii. Participatory Analysis of the Gaps}

Feedback on the baseline findings was shared with the community. This was done in order to inform the community about the observed gaps and to engage them in planning the solutions thus, ensuring the process was participatory. The feedback also involved the identification of the community trainers. The feedback meeting included 145 representatives from participating villages with 64 participants from Dodoma and 81 from Morogoro. Participants included village chairpersons, village executive officers, Hamlet leaders, health workers, primary school teachers as well as female and males' representatives from each hamlet. After the presentation of findings, participants were given opportunities to ask questions and to seek clarification. The session of questions and answers was then followed by a discussion of gaps and intervention strategies. Participants from each village shared their experiences and suggested different means of resolving the identified research gaps. To capture different views from participants, points were recorded on the flip charts and stacked on the blackboard. In general, the discussion started with probing questions like what could be the cause of a problem? Could you suggest any technique that could be used to solve the identified challenge? After listing the challenges community representatives were asked to itemize and explore issues arose. The method helped the researchers to obtain in-depth qualitative information for inclusion in the nutrition education packages. The information related to dietary challenges and their proposed solutions is shown in [Figure 1]. 


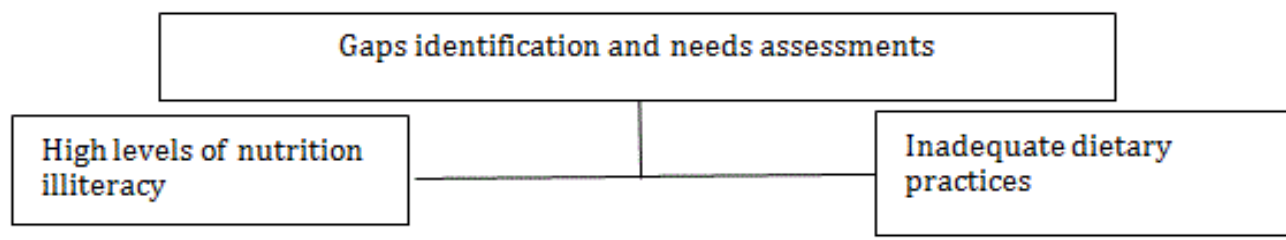

\begin{tabular}{|c|c|}
\hline $\begin{array}{l}\text {-Inadequate knowledge of malnutrition and } \\
\text { its related signs } \\
\text { - Low knowledge of food groups and their } \\
\text { functions } \\
\text {-Inadequate knowledge on portion size of } \\
\text { foods for different individuals } \\
\text { - Inadequate knowledge on individuals' foods } \\
\text { requirements } \\
\text { - Low knowledge on preservation of nutrients } \\
\text { in preparation and cooking }\end{array}$ & $\begin{array}{l}\text { - Low consumption fruits in a daily meal } \\
\text { - Low consumption of orange coloured } \\
\text { vegetables at least four times a week } \\
\text { - Low consumption of animal source foods } \\
\text { at least four times a week } \\
\text { - Low dietary diversification in a } \\
\text { household's daily meal } \\
\text { - Poor intra-household food allocation } \\
\text { - Low skills in preparation and cooking } \\
\text {-Use of non-iodized salt in cooking }\end{array}$ \\
\hline
\end{tabular}

\begin{tabular}{|l||c|}
\hline \multicolumn{1}{|c|}{ Reasons for the gaps } \\
\hline $\begin{array}{l}\text { Low coverage of nutrition } \\
\text { education }\end{array}$ & $\begin{array}{l}\text { Poor involvement of men in } \\
\text { nutrition education }\end{array}$ \\
$\qquad$ Proposed solutions \\
the identified gaps through provision of nutrition education (2). The use of \\
rs to convey nutrition messages and to increase coverage of nutrition training to the \\
volve men in nutrition education training to facilitate adoption of desirable nutrition \\
holds (4) Sustaining efforts of behaviour change in the community
\end{tabular}

Figure1: Identified Nutrition/dietary related gaps and the proposed solutions

\section{iii. Designing of Nutrition Education Training Package}

Different materials were reviewed, these included various publications related to the development and implementation of nutrition education programs, previous nutrition education packages and workshop documentations that have discussed or reviewed nutrition education programs $[6,17,18,20,22,29]$. The purpose of the review was to identify existing nutrition education materials and gaps. The information was intended to guide the drafting of nutrition education package including materials to be used. After reviewing the existing literature, the drafting of the training package was done. The package was specifically designed to address the identified gaps found during the baseline survey. A one-day stakeholders' consultation meeting was held to discuss and solicit inputs for the drafted training package including the training materials. The participants were individuals from different institutions dealing with nutrition such as universities and research centres. Other participants came from health centres, local government authorities and Non-
Government organizations. The developed training package was presented to stakeholders to solicit their opinions. The inputs from stakeholders were incorporated into the drafted training package before the pretesting. Pre-testing of the materials was done at the community level in the study villages, aspects that were considered include; the appropriateness of materials for the local context, the flow of contents, its relevance, application, clarity, and adequacy. Further, participants were asked to identify any gaps. The changes were then incorporated prior to implementation. The detailed content of the nutrition education training package is presented in[Table 1]. 


\begin{tabular}{|c|c|c|c|}
\hline Sessions & Topics & Sub-topics & Tools and materials used \\
\hline Session 1 & $\begin{array}{l}\text { Introductory } \\
\text { session }\end{array}$ & $\begin{array}{l}\text { Aim and objective of the training } \\
\text { Importance of good nutrition to the individuals, } \\
\text { households and community }\end{array}$ & $\begin{array}{l}\text { Pictorial demonstrations of healthy vs unhealthy } \\
\text { individuals }\end{array}$ \\
\hline \multirow{4}{*}{ Session 2} & \multirow{4}{*}{ Malnutrition } & Malnutrition and its different forms & $\begin{array}{l}\text { Posters and picture cards of malnutrition-related } \\
\text { signs }\end{array}$ \\
\hline & & $\begin{array}{c}\text { The magnitude of malnutrition in the study } \\
\text { villages }\end{array}$ & $\begin{array}{l}\text { Graphical presentations of the magnitude of } \\
\text { malnutrition }\end{array}$ \\
\hline & & Effects of malnutrition to the individuals & Picture cards of malnutrition-related signs \\
\hline & & Preventive measures of malnutrition & Graphical presentations of different measures \\
\hline \multirow[t]{2}{*}{ Session 3} & \multirow[t]{2}{*}{$\begin{array}{l}\text { Food preparations } \\
\text { and cooking }\end{array}$} & $\begin{array}{l}\text { Ways of preserving nutrients during food } \\
\text { preparations }\end{array}$ & $\begin{array}{l}\text { Picture cards of different methods of food } \\
\text { preparation. } \\
\text { Demonstrations of how to prepare foods }\end{array}$ \\
\hline & & Ways of preserving nutrients during cooking & Picture cards of poor vs good cooking practices \\
\hline \multirow{4}{*}{ Session 4} & \multirow{4}{*}{ Food consumption } & Food groups & Poster of different pictures of food groups \\
\hline & & Functions of each food group & Poster of different pictures of food groups \\
\hline & & How much to eat & $\begin{array}{l}\text { Posters and picture cards of portion sizes for each } \\
\text { food group }\end{array}$ \\
\hline & & Intra-household food allocation & $\begin{array}{l}\text { Poster of food allocation based on individual } \\
\text { nutritional requirements }\end{array}$ \\
\hline \multirow{2}{*}{ Session 5} & \multirow{2}{*}{$\begin{array}{l}\text { Household food } \\
\text { production }\end{array}$} & Ways of producing foods at the homestead level & $\begin{array}{l}\text { Poster of different food production methods at } \\
\text { households }\end{array}$ \\
\hline & & $\begin{array}{l}\text { Importance of homestead food production for } \\
\text { household consumption }\end{array}$ & Poster of how to use homestead produced foods \\
\hline
\end{tabular}

iv. Training

The implementation of the training involved two stages, the first stage being the training of community trainers and the second stage was the training of the targeted community. Twenty-five community trainers were identified during a feedback meeting, 6 from each village with the exception of one village which had 7 trainers. The criteria for selection of community trainers included those who participated in the baseline survey, those who are trusted by the community, those who could actively mobilize a group of people and those who had completed at least the primary level of education and could read and write. Another criterion was gender balance among trainers, this was made to ensure that men and women participate equally in delivering nutrition messages to the community. Training of trainers was done by 3 training supervisors. The supervisors had at least a bachelor's degree in human nutrition/agriculture and with vast experience with community nutrition researches and training. The identified community trainers were trained based on the content of the nutrition package developed. The trainees were given a pre-test before the training commenced. The questions were derived from different sessions of the training packages. At the end of the training, participants were given a post-test which was the same test that was given during the pre-test. This was done to evaluate their understanding. Training methods included lectures, demonstrations, practices, group discussions, roleplaying, and case studies. The community trainers were also given copies of training materials for their reference. The second stage involved training of the community, where the trained community trainers delivered the training to the targeted households. This was done in two stages; the first stage involved parallel sessions of group training conducted in 10 days by the community trainers and sessions were held in village primary schools. The second stage involved household follow-ups where the two community trainers with one supervisor visited each participant's household once a month for a consecutive 6 months in order to reinforce the nutrition messages, discussing challenges and negotiating for behaviour change. Different channels of communication were used to convey the messages during household visits. These included oral presentations, audio-visual presentations, demonstrations, display on colourful pictorial messages, and hands-on activities. Each household was given copies of colourful pictorial messages about food groups, a diversified meal, signs of malnutrition, home-stead gardening, and food preparation. The steps related to the implementation of training are shown in [Figure 2]. 


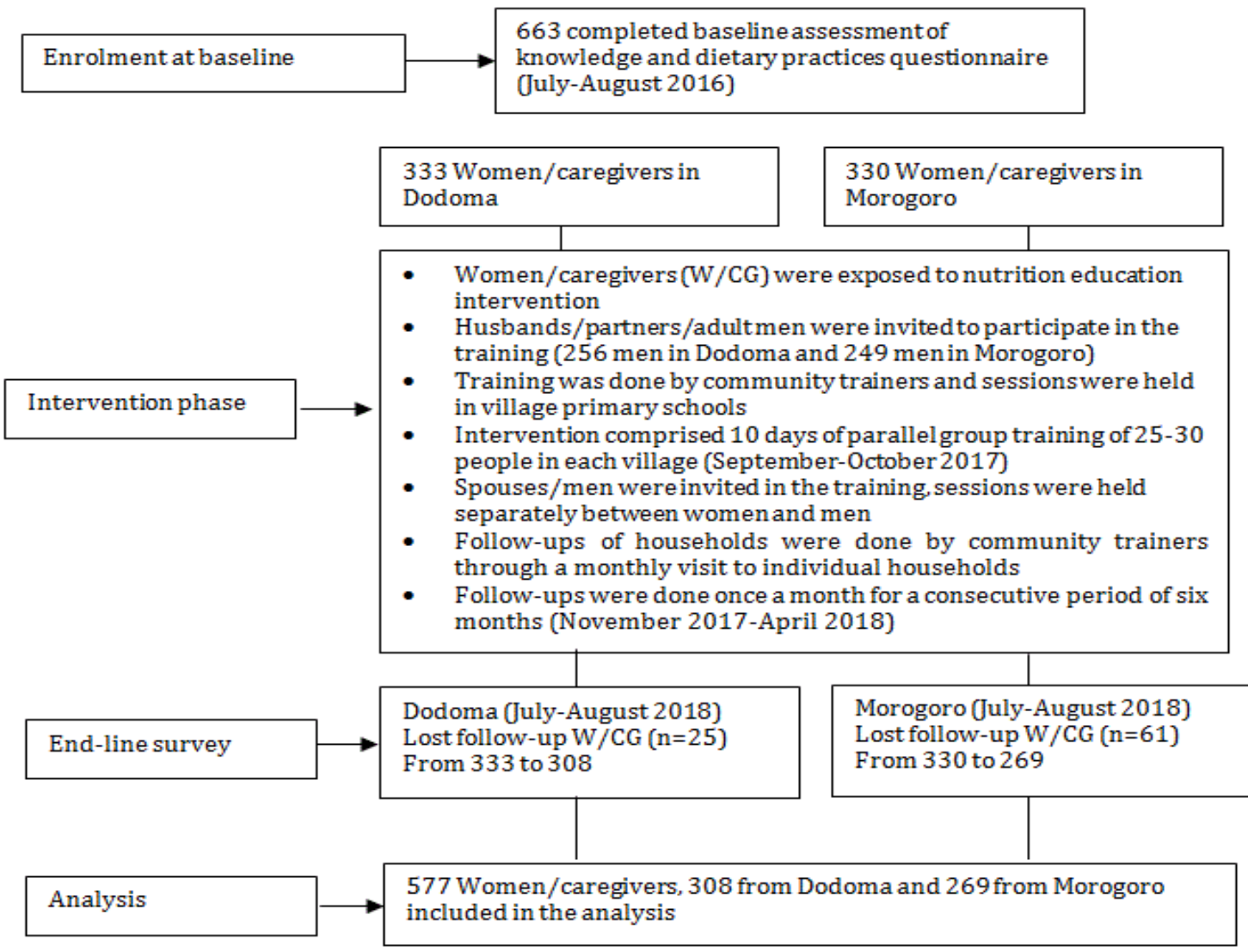

Figure 2: Processes for the implementation of nutrition education training in the study community

\section{Data Collection and Tools}

Data were principally collected during two phases, during the baseline and the end-line surveys. In both surveys, the data were collected by 10 trained field assistants who had a background of nutrition/agriculture/socio-sciences. The field assistants were guided by 2 supervisors to ensure the quality of the data collected. During the baseline survey, face-to-face interviews were carried out to establish dietary gaps. The interviews were held at village primary schools and took an average of 1 hour each. The pretested questionnaires were used to collect information. The questionnaires were designed to gather data on the demographic characteristics of the households, nutrition knowledge, nutrition-related practices, and food consumption. Similar information collected during baseline was also re-collected during the end-line survey to assess the impact of nutrition education training to the community. A descriptive summary of variables collected is described in[Table 2].

Table 2: Summary of variables collected during baseline and end-line survey in study regions

\begin{tabular}{|c|c|}
\hline Variables collected & Descriptions \\
\hline Socio-demographic & Age of mother/caregiver \\
\hline Age & $\begin{array}{c}\text { Number of years spent in } \\
\text { school }\end{array}$ \\
\hline $\begin{array}{c}\text { Education level of a mother of } \\
\text { caregivers }\end{array}$ & Ability to read \\
\hline $\begin{array}{c}\text { Level of literacy of mother of } \\
\text { caregivers }\end{array}$ & Married/cohabited or single \\
\hline Marital status
\end{tabular}

\begin{tabular}{|c|c|}
\hline Household size & $\begin{array}{c}\text { Number of people living in } \\
\text { the household }\end{array}$ \\
\hline Headship of household & Sex of household head \\
\hline Size of land owned & Land size in acreage \\
\hline Income & Monthly average income \\
\hline Nutrition knowledge (NK) & $\begin{array}{c}\text { Received or not received } \\
\text { nutrition education }\end{array}$ \\
\hline Exposure to nutrition education & $\begin{array}{c}\text { Able to mention at least one } \\
\text { malnutrition sign }\end{array}$ \\
\hline Recognition of malnutrition signs
\end{tabular}




\begin{tabular}{|c|c|}
\hline Heard about anaemia & $\begin{array}{l}\text { Able to explain what } \\
\text { anaemia is }\end{array}$ \\
\hline Had knowledge on food groups & $\begin{array}{l}\text { Can name at least two food } \\
\text { groups or can explain the } \\
\text { meaning of food group }\end{array}$ \\
\hline $\begin{array}{c}\text { Had knowledge of orange coloured } \\
\text { fruits }\end{array}$ & $\begin{array}{l}\text { Know the importance of } \\
\text { orange coloured fruits }\end{array}$ \\
\hline $\begin{array}{c}\text { Had knowledge of foods rich in dietary } \\
\text { fibre }\end{array}$ & $\begin{array}{l}\text { Mentioned foods which } \\
\text { contain high dietary fibre }\end{array}$ \\
\hline $\begin{array}{l}\text { Know the foods that increase the iron } \\
\text { uptake }\end{array}$ & $\begin{array}{l}\text { Mentioned foods that help } \\
\text { to increase the use of iron in } \\
\text { the body }\end{array}$ \\
\hline Can recognise iodized salt & $\begin{array}{l}\text { Identified iodized salt for } \\
\text { household consumption }\end{array}$ \\
\hline $\begin{array}{l}\text { Know the importance of homestead } \\
\text { livestock production for consumption }\end{array}$ & $\begin{array}{l}\text { Mentioned importance } \\
\text { of homestead livestock } \\
\text { production for animal } \\
\text { source food consumption }\end{array}$ \\
\hline $\begin{array}{c}\text { Know the importance of homestead } \\
\text { vegetable production for consumption }\end{array}$ & $\begin{array}{l}\text { Mentioned importance of } \\
\text { growing vegetables for } \\
\text { household consumption }\end{array}$ \\
\hline \multicolumn{2}{|l|}{ Nutrition Practice (NP) } \\
\hline $\begin{array}{c}\text { Translate nutrition messages taught } \\
\text { into action }\end{array}$ & $\begin{array}{l}\text { Able to implement at least } \\
\text { one of nutrition messages } \\
\text { taught }\end{array}$ \\
\hline Sought help for malnutrition & $\begin{array}{l}\text { Received professional for } \\
\text { malnutrition-related signs }\end{array}$ \\
\hline Took measures to prevent anaemia & $\begin{array}{c}\text { Took iron supplements and/ } \\
\text { deworming for prevention } \\
\text { of anaemia }\end{array}$ \\
\hline $\begin{array}{l}\text { Consumed at least five food groups in } \\
\text { a meal }\end{array}$ & $\begin{array}{c}\text { Ate at least five food groups } \\
\text { in a meal taken } 24 \text { hours } \\
\text { prior to the survey }\end{array}$ \\
\hline Consumed orange-coloured fruits & $\begin{array}{c}\text { Ate orange-coloured fruits at } \\
\text { least four times a week }\end{array}$ \\
\hline Consumed high dietary fibre rich foods & $\begin{array}{l}\text { Ate high dietary fibre rich } \\
\text { foods such as fruits in } 24 \\
\text { hours prior to the survey }\end{array}$ \\
\hline $\begin{array}{l}\text { Consumed foods that help to increase } \\
\text { the use of iron in the body }\end{array}$ & $\begin{array}{l}\text { Ate foods that help to } \\
\text { increase the use of iron in } \\
\text { the body (such as citrus } \\
\text { fruits) at least four times a } \\
\text { week }\end{array}$ \\
\hline $\begin{array}{l}\text { Used iodized salt for cooking a } \\
\text { household meal }\end{array}$ & $\begin{array}{c}\text { Used iodized salt for cooking } \\
\text { a household meal in } 24 \\
\text { hours prior to the survey }\end{array}$ \\
\hline $\begin{array}{l}\text { Consumed at least poultry or poultry } \\
\text { product at a household }\end{array}$ & $\begin{array}{l}\text { Consumed at least poultry } \\
\text { or poultry product at a } \\
\text { household at least four times } \\
\text { a week }\end{array}$ \\
\hline
\end{tabular}

\begin{tabular}{|c|c|}
\hline $\begin{array}{c}\text { Consumed at least one type of } \\
\text { vegetable at homestead level }\end{array}$ & $\begin{array}{c}\text { Consumed at least one type } \\
\text { of vegetable at homestead } \\
\text { level in 24 hours prior to the } \\
\text { survey }\end{array}$ \\
\hline Measurements of food intake & A woman/caregiver was \\
asked to recall each food \\
item consumed by the \\
household in a reference \\
period of one week prior \\
to the survey. The foods \\
were then grouped into: \\
(i)Cereals (ii)Roots tubers \\
and plantains (iii) Legumes, \\
pulses and nuts (iv) \\
Fegetables (v) Fruits (vi) \\
Meat and meat organs (vii) \\
Fish, sardines and seafoods, \\
(viii)Eggs (ix)Dairy and \\
dairy products (x)Fats and \\
oil (xi)Sugar
\end{tabular}

\section{Statistical Analysis}

Analysis of Nutrition Knowledge and Practice (NKP) uses a scoring method as described by FAO [7]. For scoring of nutrition knowledge $(\mathrm{NK})$, we computed a score ranging between 0 and 10. The scores reflected a total of $10 \mathrm{NK}$ responses, with each earning a score of 1 for a correct response and a score of 0 for an incorrect response or if a respondent was not aware of the question asked. We did the same for NP scores, where a score range of 0-10 was computed, these scores reflecting a total of 10 NP responses. The score of 1 was given for desirable nutrition/ dietary practice and the score of 0 was given for undesirable nutrition/dietary practices. The scores for both NK and NP were summed up to obtain NKP; the computed score range for NKP was $0-20$. The data were analysed using SPSS 20, scores for NK, NP and NKP were shown to be skewed (using Shapiro test), and therefore were presented as median with interquartile range (25th and 75th percentiles). The median scores before and after the intervention were compared using the Wilcoxon signed ranks test. Further comparison of NKP score with different sub-groups of respondents was done using Mann-Whitney U, for comparison of two groups and Kruskal Wallis test for comparison of more than two groups. The McNemar test was applied to establish differences in frequencies of consumption of various food items during baseline and end-line.

\section{Results}

Out of 663 women/caregivers interviewed in the baseline survey prior to nutrition education intervention, 577 were successfully assessed in the post-intervention phase during the end-line survey. Thus, the study was able to reach about $87 \%$ of the target population who completed the assessment of nutrition 
knowledge and dietary practices in both surveys. The majority of the study participants were mothers of older than 35 years. Over $75 \%$ of households during both the baseline and end-line surveys were headed by males. At baseline, only $14 \%$ of the study population reported having received nutrition education compared to $91 \%$ during the end-line [Table 3].

\begin{tabular}{|c|c|c|c|c|}
\hline & \multicolumn{2}{|c|}{$\begin{array}{c}\text { Baseline } \\
n=663\end{array}$} & \multicolumn{2}{|c|}{$\begin{array}{c}\text { End-line } \\
\mathrm{n}=\mathbf{5 7 7}\end{array}$} \\
\hline & $\mathbf{n}$ & $\%$ & $\mathbf{n}$ & $\%$ \\
\hline $\begin{array}{l}\text { Status of respondent } \\
\qquad \text { Mother } \\
\text { Caregiver }\end{array}$ & $\begin{array}{l}562 \\
101\end{array}$ & $\begin{array}{l}85 \\
15\end{array}$ & $\begin{array}{c}491 \\
86\end{array}$ & $\begin{array}{l}85 \\
15\end{array}$ \\
\hline $\begin{array}{c}15-35 \text { years } \\
36 \text { years and above }\end{array}$ & $\begin{array}{l}322 \\
341\end{array}$ & $\begin{array}{l}49 \\
51\end{array}$ & $\begin{array}{l}231 \\
346\end{array}$ & $\begin{array}{l}40 \\
60\end{array}$ \\
\hline $\begin{array}{l}\text { Headship of household } \\
\text { Female } \\
\text { Male }\end{array}$ & $\begin{array}{l}156 \\
507\end{array}$ & $\begin{array}{l}24 \\
76\end{array}$ & $\begin{array}{l}137 \\
440\end{array}$ & $\begin{array}{l}24 \\
76\end{array}$ \\
\hline $\begin{array}{l}\text { Married/cohabited } \\
\text { Single/Separated } \\
\text { Widowed }\end{array}$ & $\begin{array}{c}513 \\
92 \\
58\end{array}$ & $\begin{array}{c}77 \\
14 \\
9\end{array}$ & $\begin{array}{c}443 \\
78 \\
56\end{array}$ & $\begin{array}{l}77 \\
13 \\
10\end{array}$ \\
\hline $\begin{array}{c}\text { Number of people living in a household } \\
1-4 \text { people } \\
4 \text { people and above }\end{array}$ & $\begin{array}{l}177 \\
486\end{array}$ & $\begin{array}{l}27 \\
73\end{array}$ & $\begin{array}{l}139 \\
438\end{array}$ & $\begin{array}{l}24 \\
76\end{array}$ \\
\hline $\begin{array}{c}\text { Education level of Mother/Caregiver } \\
\qquad \text { Had formal education } \\
\text { Had no formal education }\end{array}$ & $\begin{array}{l}380 \\
283\end{array}$ & $\begin{array}{l}57 \\
43\end{array}$ & $\begin{array}{l}344 \\
233\end{array}$ & $\begin{array}{l}60 \\
40\end{array}$ \\
\hline $\begin{array}{l}\text { Exposed to nutrition education } \\
\qquad \begin{array}{c}\text { Yes } \\
\text { No }\end{array}\end{array}$ & $\begin{array}{c}93 \\
570\end{array}$ & $\begin{array}{l}14 \\
86\end{array}$ & $\begin{array}{c}523 \\
54\end{array}$ & $\begin{array}{c}91 \\
9\end{array}$ \\
\hline $\begin{array}{l}\text { Dodoma } \\
\text { Morogoro }\end{array}$ & $\begin{array}{l}333 \\
330\end{array}$ & $\begin{array}{l}50 \\
50\end{array}$ & $\begin{array}{l}308 \\
269\end{array}$ & $\begin{array}{l}53 \\
47\end{array}$ \\
\hline $\begin{array}{l}\text { Mzula } \\
\text { Chinoje } \\
\text { Tindiga } \\
\text { Mhenda }\end{array}$ & $\begin{array}{l}167 \\
166 \\
166 \\
164\end{array}$ & $\begin{array}{l}25 \\
25 \\
25 \\
25\end{array}$ & $\begin{array}{l}158 \\
150 \\
141 \\
128\end{array}$ & $\begin{array}{l}27 \\
26 \\
25 \\
22\end{array}$ \\
\hline
\end{tabular}

\section{Nutrition Knowledge Indicators at Baseline and End-Line}

Key indicators for nutrition knowledge of mothers/caregivers at the baseline and end-line are presented in [Figure 3]. Generally, the majority of women/caregivers responded more correctly to the questions related to various aspects of nutrition knowledge in the post-intervention phase (end-line) than prior to the intervention (baseline). Knowledge regarding signs of malnutrition, food groups, dietary enhancers of iron absorption, and the identification of iodised salt increased from baseline to end-line. Although knowledge regarding the importance of vegetable consumption was high during the baseline (72\%), but a slight increase was noted during the end-line $82 \%$.

\section{Nutrition Practice Indicators at Baseline and End-Line}

Figure 4 represents the key indicators for the nutrition practice of mothers/caregivers at the baseline and end-line. At the baseline, only $8 \%$ of mothers/caregivers were able to translate some nutrition messages received from health centres into practice. The increase in percentage (84\%) of those who were able to implement the taught nutrition messages was seen during the end-line, following the implementation of nutrition education intervention. Almost half (54\%) of mothers/caregivers reported 


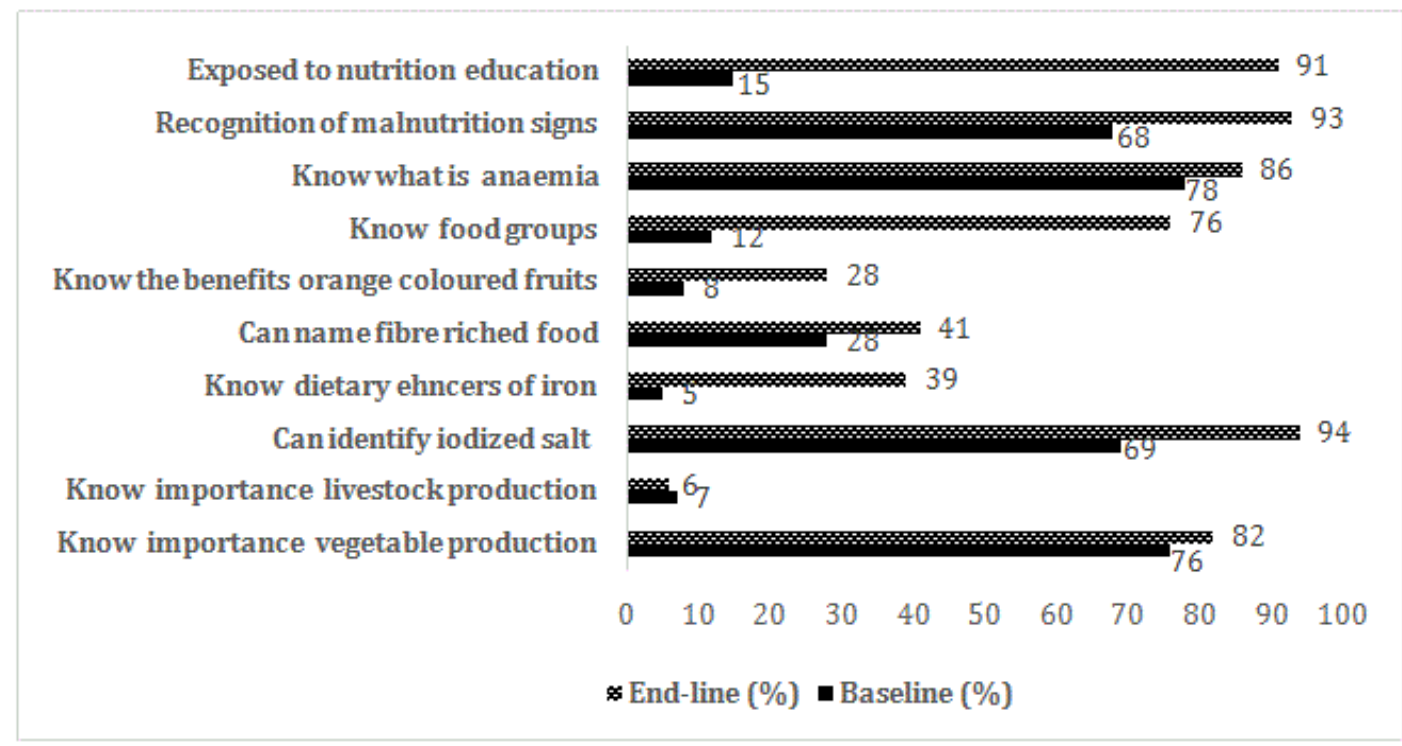

Figure 3: Nutrition knowledge indicators at baseline and end-line, values are presented as percentages of correct responses. The sample comprises only those who participated in both the baseline and end-line surveys (577)

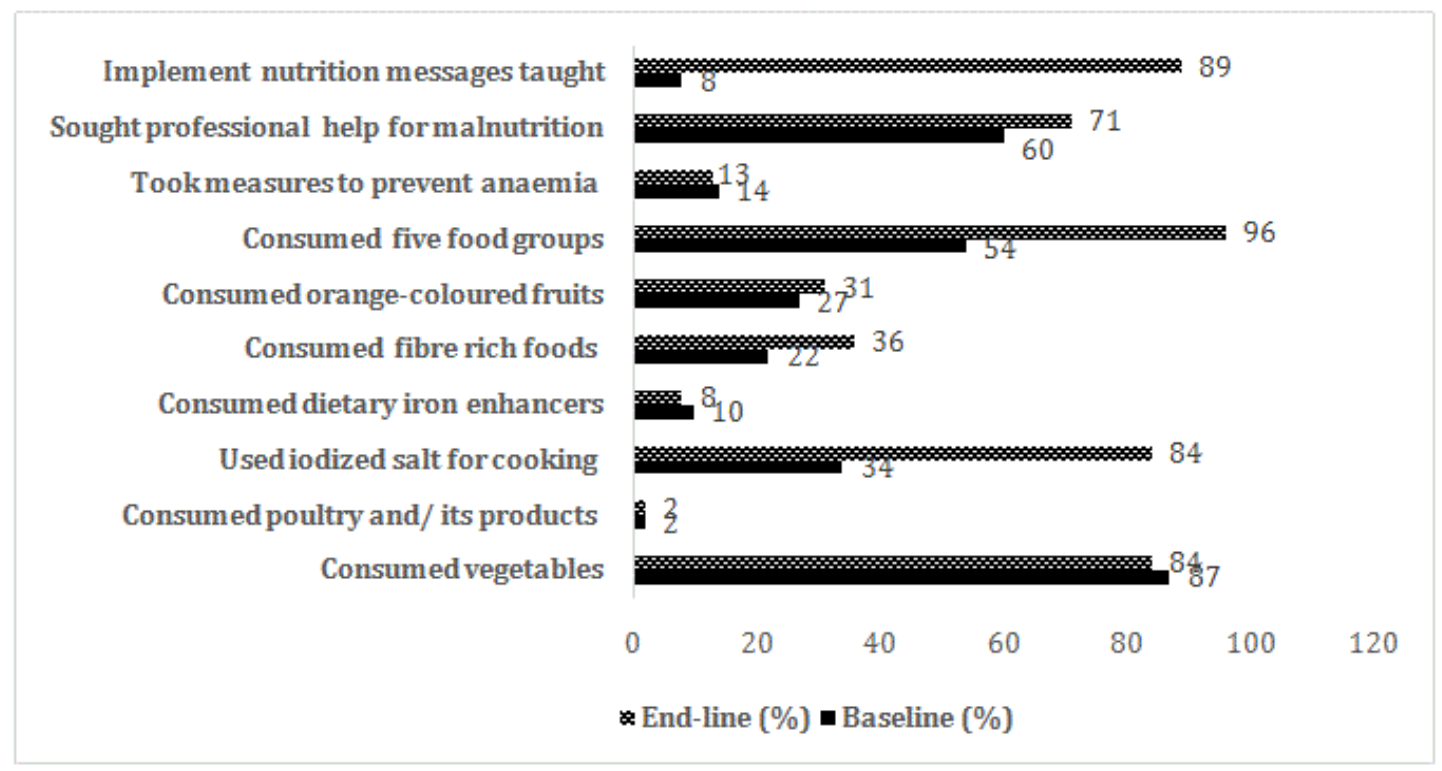

Figure 4: Nutrition practice indicators at baseline and end-linevalues are presented as percentages of correct responses. The sample comprises only those who participated in both the baseline and end-line surveys (577)

having included at least 5 food groups in their household meal during baseline and $96 \%$ in the end-line. Despite the changes, consumption of poultry and poultry products was minimum both at the baseline and end-line (2\%).

\section{NKP Scores at the Baseline and End-Line in the Study Regions}

Table 4 shows the median scores of knowledge, practice as well as the total knowledge and practice scores of respondents at baseline and end-line. A significant improvement of scores for knowledge and practice was seen in all regions after the intervention. The median NKP score for end-line was higher (12.2) compared to the baseline NKP scores 7.0 as shown in [Table 4].

\section{Frequency of Food Consumption at Baseline and End-Line}

The frequency of food items consumed regularly (at least five times a week) in a household is presented in [Table 5]. The proportion of those who consumed vegetables, fruits and legumes increased significantly in the post-intervention phase compared to the pre-intervention phase $(98 \%$, vs $87 \%, 69$ vs $63 \%$ and 87 vs 
$76 \%, p=0.000$ ), respectively. Despite the positive changes in the consumption frequencies of vegetables, fruits and legumes, the intake of animal source foods such as meat, eggs, and dairy products did not significantly change after the intervention $(5 \%$ vs $4 \%, 1 \%$ vs $1 \%$, and $2 \%$ vs $2 \%$ ), respectively. Notably, a significant decrease in regular consumption of fish was seen during the post-intervention phase than prior to the intervention ( $9 \%$ vs $11 \%, \mathrm{p}=0.019$ ) [Table 5].

\section{Comparison of NKP Scores among Sub-Groups of Women/Caregivers at the End-Line}

There was a variation in scores between villages and regions; generally, Morogoro region had a significantly higher median NKP score (12.5) than Dodoma region (11.4), p> 0.001, likewise, Mhenda village in Morogoro region had significantly higher NKP scores than the remaining villages. Variations of scores were also seen among different groups of respondents, including those who had received nutrition education, those who had frequently been exposed to nutrition education, those whose spouse/men participated in nutrition education and those who had a formal level of education compared to their counterparts. In addition, the scores were found to be the same across different age categories, household sizes and marital status as shown in [Table 6].

Table 4: NKP scores for the baseline and end-line in the study regions

\begin{tabular}{|c|c|c|c|}
\hline Characteristic & $\begin{array}{c}\text { All Regions } \\
\text { Median (IQR) }\end{array}$ & $\begin{array}{c}\text { Dodoma } \\
\text { Median (IQR) }\end{array}$ & $\begin{array}{c}\text { Morogoro } \\
\text { Median (IQR) }\end{array}$ \\
\hline \multicolumn{4}{|c|}{ Nutrition Knowledge Score (0-10) } \\
\hline Baseline & $4.0(3.0,5.0)$ & $3.0(2.0,4.0)$ & $4.0(3.0,5.0)$ \\
\hline End-line & $7.0(5.0,7.0)^{*}$ & $6.0(5.0,7.0)^{*}$ & $7.0(5.0,8.0)^{*}$ \\
\hline \multicolumn{4}{|c|}{ Nutrition Practice Score (0-10) } \\
\hline Baseline & $3.0(2.0,4.0)$ & $2.0(1.0,3.0)$ & $4.0(3.0,5.0)$ \\
\hline End-line & $5.4(4.4,6.4)^{*}$ & $5.4(4.4,6.4)^{*}$ & $5.5(5.0,6.5)^{*}$ \\
\hline \multicolumn{4}{|c|}{ Nutrition Knowledge and Practice Score (0-20) } \\
\hline Baseline & $7.0(5.0,8.5)$ & $5.0(4.0,7.0)$ & $8.0(6.0,10.0)$ \\
\hline End-line & $12.2(10.4,13.4)^{*}$ & $11.4(9.5,13.2)^{*}$ & $12.5(11.0,14.4)^{*}$ \\
\hline
\end{tabular}

Wilcoxon signed ranks test, variables are presented as median and in parentheses, the interquartile range, values marked by ${ }^{*}$ indicate significance differences between baseline and end-line median scores $(\mathrm{p}<0.001)$

Table 5: Frequency of food consumption at baseline and end-line

\begin{tabular}{|c|c|c|c|c|c|}
\hline \multirow[t]{2}{*}{ Food items } & \multicolumn{2}{|l|}{ Baseline } & \multicolumn{2}{|l|}{ End-line } & \multirow[t]{2}{*}{ P-value } \\
\hline & $\mathbf{n}$ & $\%$ & $\mathbf{n}$ & $\%$ & \\
\hline Cereals & 574 & 99.5 & 572 & 99.1 & 0.500 \\
\hline Roots, tubers and plantains & 138 & 23.9 & 152 & 26.3 & 0.001 \\
\hline Legumes, pulses and nuts & 441 & 76.4 & 499 & 86.5 & $<0.001$ \\
\hline Vegetables (fresh and dried vegetables) & 503 & 87.2 & 564 & 97.7 & $<0.001$ \\
\hline Fruits & 365 & 63.3 & 396 & 68.8 & $<0.001$ \\
\hline Meat (beef, poultry, meat organs) & 24 & 4.2 & 28 & 4.9 & 0.454 \\
\hline Fish (fresh and dried, seafoods, sardines) & 62 & 10.7 & 51 & 8.8 & 0.019 \\
\hline Eggs & 4 & 0.7 & 4 & 0.7 & 1.000 \\
\hline Fats and Oil & 324 & 56.2 & 347 & 60.1 & $<0.001$ \\
\hline Sugar & 182 & 31.5 & 202 & 35 & 0.001 \\
\hline
\end{tabular}

McNemar test, for comparison of proportions, the sample comprises only those who participated in both the baseline and end-line surveys (577). Food items presented are based on regular consumption (food items consumed at least 5 times a week) 


\begin{tabular}{|c|c|c|}
\hline Characteristic & Median NKP score & P-value \\
\hline $\begin{array}{c}\text { Dodoma } \\
\text { Morogoro }\end{array}$ & $\begin{array}{l}11.4 \\
12.5\end{array}$ & $<0.001$ \\
\hline $\begin{array}{l}\text { Mzula } \\
\text { Chinoje } \\
\text { Tindiga } \\
\text { Mhenda }\end{array}$ & $\begin{array}{l}11.8 \\
11.2 \\
12.4 \\
13.2\end{array}$ & $<0.001$ \\
\hline Status of respondent & $\begin{array}{l}12.4 \\
11.4\end{array}$ & 0.019 \\
\hline $\begin{array}{c}15-35 \text { years } \\
36 \text { years and above }\end{array}$ & $\begin{array}{l}12.4 \\
12.2\end{array}$ & 0.247 \\
\hline Headship of household• & $\begin{array}{l}12.2 \\
12.2\end{array}$ & 0.261 \\
\hline $\begin{array}{l}\text { Married/cohabited } \\
\text { Single/Separated } \\
\text { Widowed }\end{array}$ & $\begin{array}{l}12.2 \\
12.4 \\
11.8\end{array}$ & 0.439 \\
\hline $\begin{array}{l}\text { Number of people living in a household } \\
\qquad \begin{array}{l}1-4 \text { people } \\
4 \text { people and above }\end{array}\end{array}$ & $\begin{array}{l}12.2 \\
12.2\end{array}$ & 0.624 \\
\hline $\begin{array}{l}\text { The education level of Mother/Caregiver } \\
\qquad \text { Had formal education } \\
\text { Had no formal education }\end{array}$ & $\begin{array}{l}12.2 \\
11.2\end{array}$ & $<0.001$ \\
\hline $\begin{array}{l}\text { Exposure to nutrition education } \\
\qquad \begin{array}{r}\text { Yes } \\
\text { No }\end{array}\end{array}$ & $\begin{array}{c}12.4 \\
9\end{array}$ & $<0.001$ \\
\hline $\begin{array}{l}\text { Participation of spouse/male in nutrition education } \\
\qquad \begin{array}{c}\text { Yes } \\
\text { No }\end{array}\end{array}$ & $\begin{array}{c}12.5 \\
9.5\end{array}$ & $<0.001$ \\
\hline $\begin{array}{l}\text { Frequency of receiving nutrition education } \\
\qquad \begin{array}{l}\text { Up to } 3 \text { times } \\
\text { More than } 3 \text { times }\end{array}\end{array}$ & $\begin{array}{l}11.5 \\
12.4\end{array}$ & $<0.001$ \\
\hline
\end{tabular}




\section{Discussion}

\section{Effect of Nutrition Education on Nutrition Knowledge and Practice Scores}

The findings of this study indicate that nutrition education intervention effectively improves nutrition knowledge and dietary practice among mothers/caregivers in rural households. Aspects of knowledge and practices that improved are; recognition of malnutrition conditions and signs, the importance of food groups in diversifying diet, nutrition importance fruits, importance of vegetables, dietary enhancers of iron and the use of iodized salt. In our study, we found an increase in the number of participants who responded correctly to the questions related to nutrition knowledge and practice in the end-line survey compared to the baseline; this ultimately contributes to the increase of the nutrition knowledge and practice scores following the implementation of nutrition education. These findings are similar to other studies that reported a significant improvement of knowledge and practice scores with an increase in the percentage of correct responses regarding nutrition knowledge and practice questions after implementation of a nutrition education programme [25,30,31,32]. Likewise, Cannoosamy et al. reported a positive mean change of nutrition knowledge scores and an increase of desirable dietary practices such as fruits and vegetable consumption following the implementation of a nutrition education intervention among housewives in Mauritius[33]. The positive changes to nutrition knowledge and dietary practices observed in this study could be as a result of the multiple approaches used in conveying the nutrition education intervention to our study population. For example, the use of community trainers who are trusted and familiar with the study community helped to reach the community and convey nutrition messages easily. In addition, the involvement of spouses/men in nutrition training helped the retention of knowledge at the household level. Further, the use of different communication methods including presentations, demonstrations, and dialogues helped multiple transmission of nutrition education messages. In addition, the approach of individual household follow-ups also helped to discuss challenges, clarify misconceptions and negotiate for behaviour change within the targeted households. Studies from different literature concluded on the effectiveness of multi-strategy approaches used in delivering nutrition messages and achieving behaviour change to the targeted community $[34,35,36]$.

\section{Food Consumption Before and After Nutrition Education}

Consumption frequencies of different food groups such as; vegetables, fruits, and legumes increased significantly after the implementation of the nutrition education intervention. The finding implies that if people are empowered with appropriate nutrition information, they are able to make informed dietary choices and modify their dietary habits. This finding concurs with that of Mahmudiono et al., who examined the impact of nutrition education on dietary related behaviour among obese women[37].
The authors found an improvement in the intake of fruits and vegetables among women in response to the provided nutrition education. Despite the positive dietary changes found in our study, the frequency of the intake of animal source foods such as meat, milk, eggs, and fish did not improve after the intervention. We found the same trend of low consumption of animal source foods prior to the implementation of nutrition education intervention. We showed in our previous findings that about $50 \%$ of the surveyed households had livestock in their homestead, but only a quarter of them consumed at least one animal source food in the 24 hours preceding the survey date[38]. We explained, further in our previous findings that slaughtering of livestock for household consumption or consumption of livestock products such as milk and eggs is not usually practiced, and whenever it is done there should be a justifiable reason such as ceremonial celebrations, holidays or when a household gets an important visitor/guest. Otherwise, the livestock is sold to get immediate cash or exchanged for important services like the milling of cereal grains, paying for water services or medical bills [38]. These results concurred with the findings of Nyantakyi-Frimpong et al., who elaborated on the cultural and economic values embedded in livestock among livestock keepers in Ghana, constrained optimal consumption of animal source foods[39]. These findings necessitate the need for designing long-term nutrition behaviour change strategies that promote and sustain the consumption of animal source foods in rural households.

\section{NKP Scores Among Sub-Groups of Study Participants}

A significant variation of scores was seen among different sub-groups of respondents. Those who reported having received nutrition education had higher nutrition knowledge and practice scores compared to those who did not receive nutrition education. Additionally, the scores were higher among the respondents who had attended nutrition education sessions more than three times compared to those who attended less frequently (less than three times). A study by Anetor et al., demonstrated the positive changes of knowledge and dietary practices to those participants who were exposed to nutrition education versus those participants who were not exposed[31]. Contento links the frequency of exposure to nutrition education, or repetition of nutrition messages to the community, with retention of nutrition knowledge and adoption of desirable dietary practices by the community [17]. Furthermore, the scores for both knowledge and practice were higher for mothers/caregivers who had a formal level of education than their counterparts. A similar observation was made by Christian et al., among 608 caregivers in rural parts of Ghana, where caregivers with a formal level of education had higher nutrition knowledge scores and higher dietary diversity than those who did not have a formal level of education[40]. However other studies indicated that the effects of the formal education on dietary practices can be seen indirectly through the improvement of socio-economic status such as increased purchasing power and access to diverse food choices [41,42]. The higher knowledge and practice scores were also noted among the group of mothers/caregivers who brought their spouse/ 
men to participate in the nutrition education intervention than their counterparts. This finding confirms what is found in other studies where a low priority accorded to household nutrition was found among men who were less involved in nutrition or those with low knowledge of nutrition than their counterparts[43,44]. In the present study, the felt need for contextualisation of barriers to nutrition knowledge and dietary practices came out vividly in the study villages and regions. The differences in knowledge and practice scores seen between study villages and regions call for further investigation of enhancers and barriers to the acquisition of knowledge and adoption of desirable dietary practices in specific regions and villages.

This study has some limitations; The data for this study relied on self-reporting; hence it is difficult to control bias as the respondents may give information which they think is widely acceptable. Although this study used a large sample size and gives useful findings that can guide future designing of nutrition programs in areas with similar settings, the information cannot be generalized to other areas with different contextual settings, hence further studies in other areas with different settings are necessary. Furthermore, this study primarily targeted women/caregivers, who are involved directly in household food preparations cooking and allocation hence there is no comparison between male and female in terms of levels of nutrition knowledge and practice

\section{Conclusion}

The findings of our study signify the positive effect of nutrition education in the promotion of nutrition knowledge and desirable dietary practices in rural families of Tanzania. The aspects of knowledge regarding malnutrition, food groups, and their function, nutrition importance fruits and vegetables, dietary enhancers of iron and the use of iodized salt increased after the intervention. Likewise, the aspects of nutrition practices such as consumption frequencies of vegetables, fruits, and legumes increased significantly after the intervention. The low consumption of animal source foods remains a challenge even after the implementation of the nutrition education intervention in our study population, this calls for further investigations on specific behaviour change program to address the issue. Our study underscores the need to involve spouses/men in nutrition education programmes to facilitate the retention of nutrition knowledge and the adoption of desirable dietary practices in households. We conclude that the nutrition education intervention among our study population provided the desired changes and that the approaches used in delivering nutrition messages to the community can inform the future designing of nutrition education interventions in other areas with similar settings.

\section{Conflict of interest}

The authors of this article declare no conflict of interest.

\section{Acknowledgment}

The authors would like to acknowledge the financial support from the Scale-N project, funded by Germany Federal Ministry of Food and Agriculture (BMLE) based on a decision by the parliament of the Federal Republic of Germany through the Federal Office for Agriculture and Food (BLE). The funders had no role in the study design, data collection, analysis or decision to publish. We are grateful to the villagers and rural community in both from Dodoma and Morogoro regions, for their willingness to participate in the study and providing the required information.

\section{Author Contributions}

NB contributed conception and design of the study, organized the database, and performed the statistical analysis; NB wrote the first draft of the manuscript; JK, TJ, WS CR and SS critically reviewed and refined the manuscript. All authors contributed to manuscript revision, reading and approving the final submitted version of the manuscript.

\section{Availability of data}

Data used in this study can be made available up on request.

\section{References}

1. Development Initiatives. Global Nutrition Report 2018: Shining a light to spur action on nutrition. Bristol, UK; 2018 Development Initiatives.

2. Saunders J, Smith T. Malnutrition: causes and consequences. Clin Med (Lond). 2010;10(6):624-627. doi:10.7861/clinmedicine.10-6-624.

3. UNICEF. United Nations Children's Fund. Strategy for improved nutrition of children and women in developing countries. New York: UNICEF, 1990.

4. Kalkan I. The impact of nutrition literacy on the food habits among young adults in Turkey. Nutr Res Pract. 2019;13(4):352-357. doi: 10.4162/nrp.2019.13.4.352.

5. FAO. Food and Agriculture Organization of the United Nations. KAP manual: guidelines for assessing nutrition related knowledge, attitudes and practices. Rhome, Italy: Nutrition Division, Food and Agriculture Organization of the United Nations (FAO). Viale delle Terme di Caracalla, Rhome Italy; 2014;188p.

6. Hawkes C. Promoting healthy diets through nutrition education and changes in the food environment: an international review of actions and their effectiveness. Rome: Nutrition Education and Consumer Awareness Group, Food and Agriculture Organization. 2013.

7. Bundala N, Kinabo J, Jumbe T, Bonatti M, Rybak C, et al. Gaps in knowledge and practice on dietary consumption among rural farming households; A call for nutrition education training in Tanzania. Int J Food Sci Nutr. 2019; 1-11. doi: 10.1080/09637486.2019.1655533

8. Keflie TS, Samuel A, Lambert C, Nohr D, Biesalski H K. Dietary Patterns and Risk of Micronutrient Deficiencies: their Implication for Nutritional Intervention in Ethiopia. J Nutrition Health Food Sci. 2018;6(1):1-16. doi: 10.15226/jnhfs.2018.001120

9. Branca F, Lartey A, Oenema S, Aguayo V, Stordalen GA, Richardson $\mathrm{R}$, et al. Transforming the food system to fight non-communicable diseases. BMJ. 2019; 364:1296. doi: https://doi.org/10.1136/bmj. 
1296

10. Walson JL, Berkley JA. The impact of malnutrition on childhood infections. Curr Opin Infect Dis. 2018 ;31(3):231-236. doi: 10.1097/ QCO.0000000000000448

11. Martins VJB, Toledo Florêncio TM, Grillo LP, Grillo LP, Franco Mdo C, Martins PA, et al. Long-lasting effects of undernutrition. Int J Environ Res Public Health 2011;8(6):1817-1846. doi: 10.3390/ijerph8061817

12. UNSCN. United Nations System Standing Committee on Nutrition. Non-communicable diseases, diets and nutrition. 2018;1-12.

13. Ministry of Health, Community Development, Gender, Elderly and Children (MoHCDGEC) [Tanzania Main land], Ministry of Health $(\mathrm{MoH})$ [Zanzibar], Tanzania Food and Nutrition Centre (TFNC), National Bureau of Statistics (NBS), Office of the Chief Government Statistician (OCGS) [Zanzibar] and UNICEF. Tanzania National Nutrition Survey using SMART Methodology (TNNS) 2018. Dares Salaam, Tanzania: MoHCDGEC, MoH, TFNC, NBS, OCGS, and UNICEF. 14. TDHS-MIS-2015/2016. Tanzania Demographic and Health Survey 2015. NBS and ICF Macro. Dar es Salaam, Tanzania.

15. URT 2016. United Republic of Tanzania, National Multi sectoral Nutrition Action Plan (NMNAP), JULY 2016 -JUNE 2021. From Evidence to Policy to Action. Dar-es-salaam Tanzania.

16. Kennedy E, Stickland J, Kershaw, M, Biadgilign S. Impact of Social and Behaviour Change Communication in Nutrition Sensitive Interventions on Selected Indicators of Nutritional Status. J Hum Nutr. 2018;2(1):24-33. doi: 10.36959/487/279

17. Contento IR. Nutrition Education: Linking Research, Theory, and Practice (3rd edition). Sudbury, MA: Jones and Bartlett Publishers, 2016.

18. Mbwana H, Kinabo J, Lambert C, Biesalski HK. Determinants of household dietary practices in rural Tanzania: Implications for nutrition interventions. Cogent Food and Agriculture. 2016;2(1):1224046

19. Nabugoomu J, Namutebi A, Kaaya AN, Nasinyama G. Nutrition Education Influences Child Feeding Knowledge Attitudes and Practices of Caregivers in Uganda. Am J Health Res. 2015;3(2):82-90. doi. 10.11648/j.ajhr.20150302.15

20. Kulwa KB, Verstraeten R, Bouckaert KP, Mamiro PS, Kolsteren PW, Lachat $\mathrm{C}$. Effectiveness of a nutrition education package in improving feeding practices, dietary adequacy and growth of infants and young children in rural Tanzania: rationale, design and methods of a cluster randomised trial. BMC Public Health. 2014;14:1077. doi: 10.1186/1471-2458-14-1077

21. Kinabo J, Mwanri A, Mamiro P, Kulwa K, Bundala N, Picado J, et al. Infant and Young Child Feeding practices on Unguja Island in Zanzibar, Tanzania: a Propan based analysis. Tanzania Journal of Health Research. 2017;19(3):1-9.

22. Pillai A, Kinabo J, Krawinkel MB. Effect of nutrition education on the knowledge scores of urban households with home gardens in Morogoro, Tanzania. Agriculture \& Food Security. 2016;5(1): 22.

23. Ruhembe CC, Mosha TCE, Nyaruhucha CNM. Risk Factors Associated with Elevated Blood Glucose Among Adults in Mwanza City. Tanzania, Tanzania Journal of Agricultural Sciences. 2015; 14(2):90-100.

24. Msuya JM, Kaganda J, Maurice RB. Nutrition research agenda in the context of nutrition problems in Tanzania - a critical review. Tanzania
Journal of Agricultural Sciences. 2015;14(1):78-89.

25. Young S, Israel-Ballard K, Dantzer E, Ngonyani M, Nyambo M, Ash D, et al. Infant feeding practices among HIV-positive women in Dar es Salaam, Tanzania, indicate a need for more intensive infant feeding counselling. Public Health Nutr. 2010;13(12): 2027-2033. doi. $10.1017 /$ S1368980010001539

26. Stuetz W, Gowele V, Kinabo J, Bundala N, Mbwana H, Rybak C, et al. Consumption of Dark Green Leafy Vegetables Predicts Vitamin $\mathrm{A}$ and Iron Intake and Status among Female Small-Scale Farmers in Tanzania. Nutrients. 2019;11(5): pii: E1025. doi: 10.3390/ nu11051025

27. Scale N. Scaling up Nutrition, implementing potential of nutrition sensitive diversified agriculture to improve nutrition project. 2016.

28. National Bureau of Statistics (NBS). Environment Statistics 2015; United Republic of Tanzania: Dar es Salaam, Tanzania, 2015.

29. Smith B, Smitasiri S. A framework for nutrition education programmes. In: Nutrition education for the public - Discussion papers of the FAO Expert Consultation (No. 62). Rome: FAO; 1997.

30. Yahia N, Brown CA, Rapley M, Chung M. Level of nutrition knowledge and its association with fat consumption among college students. BMC Public Health. 2016;16(1):1047. doi: 10.1186/s12889-0163728-z

31. Anector GO, Ogundele BO, Oyewole OE. Effect of nutrition education on the eating habits of undergraduates in south-west Nigeria. Asian Journal of Epidemiology. 2012;5(2):32-41.

32. Inayati DA, Scherbaum V, Purwestri RC, Wirawan NN, Suryantan J, Hartono $S$, et al. Improved nutrition knowledge and practice through intensive nutrition education: A study among caregivers of mildly wasted children on Nias Island, Indonesia. Food Nutr Bull. 2012; 33(2):117-127.

33. Cannoosamy K, Pem D, Bhagwant S, Jeewon R. Is a Nutrition Education Intervention Associated with a Higher Intake of Fruit and Vegetables and Improved Nutritional Knowledge among Housewives in Mauritius?. Nutrients. 2016;8(12):E723. doi:10.3390/nu8120723

34. Myszkowska-Ryciak J, Harton A. Eating Healthy, Growing Healthy: Impact of a Multi-Strategy Nutrition Education on the Assortments of Beverages Served in Preschools, Poland. Int J Environ Res Public Health. 2018;15 (7):1355. doi: 10.3390/ijerph15071355

35. Dudley DA, Cotton WG, Peralta LR. Teaching approaches and strategies that promote healthy eating in primary school children: a systematic review and meta-analysis. Int J Behav Nutr Phys Act. 2015;12:28. doi: 10.1186/s12966-015-0182-8

36. Shahril MR, Dali WPEW, Lua PL. A 10-Week Multimodal Nutrition Education Intervention Improves Dietary Intake among University Students: Cluster Randomised Controlled Trial. J Nutr Met. 2013;111.

37. Mahmudiono T, Mamun AA, Nindya TS, Andrias, DR, Megatsari H, Rosenkranz RR. The Effectiveness of Nutrition Education for Overweight/Obese Mother with Stunted Children (NEO-MOM) in Reducing the Double Burden of Malnutrition. Nutrients. 2018;10(12): pii: E1910. doi: 10.3390/nu10121910

38. Bundala N, Kinabo J, Jumbe T, Rybak C, Sieber S. Does homestead livestock production and ownership contribute to consumption of animal source foods? A pre-intervention assessment of rural farming 
communities in Tanzania. Scientific African. 2020; 7: e00252.

39. Nyantakyi-Frimpong H, Colecraft EK, Leonard B, Awauah RB, Adjorlolo LK, Wilson ML, and Jones AD. Leveraging smallholder livestock production to reduce anemia: A qualitative study of three agro-ecological zones in Ghana. Soc Sci Med. 2018; 212:191-202. doi: 10.1016/j.socscimed.2018.07.028

40. Christian AK, Marquis GS, Colecraft EK, Lartey A, Sakyi-Dawson O, Ahunu BK, et al. Caregivers' nutrition knowledge and attitudes are associated with household food diversity and children's animal source food intake across different agro-ecological zones in Ghana. Br J Nutr. 2016;115(2):351-360. doi: 10.1017/S0007114515004468

41. Pechey R, Monsivais P. Socioeconomic inequalities in the healthiness of food choices: Exploring the contributions of food expenditures.
Prev Med. 2016;88:203-209. doi: 10.1016/j.ypmed.2016.04.012

42. Heshmat R, Salehi F, Qorbani M, Rostami M, Shafiee G, Ahadi Z, et al. Economic inequality in nutritional knowledge, attitude and practice of Iranian households: The NUTRI-KAP study. Med J Islam Repub Iran. 2016;30:426.

43. Kansiime N, Atwine D, Nuwamanya S and Bagenda F. 2017. Effect of Male Involvement on the Nutritional Status of Children Less Than 5 Years: A Cross Sectional Study in a Rural South western District of Uganda. Journal of Nutrition and Metabolism. 2017;9.

44. Ochieng J, Afari-Sefa V, Lukumay PJ, Dubois T. Determinants of dietary diversity and the potential role of men in improving household nutrition in Tanzania. PLoS ONE. 2017;12(12): e0189022. 